\title{
Making Martial Arts History Matter
}

\section{Paul Bowman}

To cite this article: Paul Bowman (2016) Making Martial Arts History Matter, The International Journal of the History of Sport, 33:9, 915-933, DOI: 10.1080/09523367.2016.1212842

To link to this article: http://dx.doi.org/10.1080/09523367.2016.1212842

\section{(C) 2016 The Author(s). Published by Informa UK Limited, trading as Taylor \& Francis Group

曲 Published online: 25 Aug 2016.

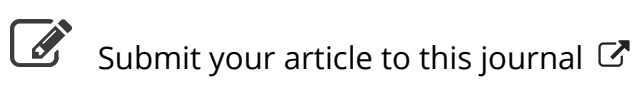

Џلll Article views: 405

Q View related articles $₫$

View Crossmark data $\nearrow$ 


\title{
Making Martial Arts History Matter
}

\author{
Paul Bowman \\ School of Journalism, Media and Cultural Studies, Cardiff University, Cardiff, UK
}

\begin{abstract}
This paper examines key ways in which ideas such as 'tradition', 'authenticity', and 'history' are deployed in discourses around Asian martial arts. First introducing how such concepts are used in national contexts such as Korea and elsewhere in East Asia it then examines the case of a dispute between two English language writers on martial arts. It examines these different cases to illustrate the ways that 'tradition','authenticity', and 'history' can be deployed for different ideological ends, from nationalism to personal self-advancement, in different contexts. In doing so, the paper theorizes the consequences of antagonisms that have recently arisen between common beliefs about certain Asian martial arts and historical studies that challenge such beliefs. It concludes that the discursive status of 'history' is not fixed or permanent, but varies depending on context. This is the case to such an extent that the status of 'history' can be said to have changed decisively. Ultimately, the paper argues for the value of rigorous scholarship even when it runs counter to cultural beliefs, and highlights the significance of such scholarship for showing the ways in which martial arts history matters in more contexts and registers than martial arts alone.
\end{abstract}

\section{KEYWORDS}

Martial arts; history; invented tradition; allochronism; orientalism

\section{Introduction: Myths of History in Martial Arts}

The topics of history, tradition, and authenticity in Asian martial arts are highly conflicted. A handful of scholars have offered well-researched martial arts histories, which challenge what are often quite obviously preposterous myths. ${ }^{1}$ Yet even the most outrageous and ludicrous of myths about Asian martial arts seem tenacious. Articles and books - both scholarly and popular - continue to be published that trade entirely in myths and legends, snake oil and sorcery, presenting them as history. ${ }^{2}$ However, with the recent increase in scholarly attention to martial arts, plus the emergence of a new field of 'martial arts studies' itself, combined with the movement of peer-reviewed publications into the open-access realm, ${ }^{3}$ one has to ask whether 'smoke and mirrors' martial arts 'histories' have a future. This paper seeks to intervene into the field of antagonisms between academic and popular approaches to martial arts, by setting out the key terms, stakes and consequences of different kinds of approach to 'traditional' martial arts, and arguing for the importance and value of a distinct kind of 
self-reflexive rigour in the development of academic martial arts studies, no matter what kind of damage such approaches appear to do to older forms of engagement with them. As Henning writes in 'On Politically Correct Treatment of Myths in Chinese Martial Arts':

There is a rising trend in the 'Occidental' world of 'Oriental' martial arts - the number of 'scholars' who, in spite of making pretenses to upholding 'academic standards', are displaying no small amount of intellectual compromise by acting as apologists for the myths surrounding the Chinese martial arts. They do this in a manner which gives one the impression that they somehow feel that to expose these myths is an irreverent act, harming the sensitivities of the Chinese people and insulting to pseudo-intellectual Occidentals seeking a New Age refuge in Oriental mysticism or, worse yet, causing them to lose interest in a subject about which these 'scholars' delight in composing involved, ambiguous treatises. ${ }^{4}$

Unfortunately, neither pseudo-histories nor the 'politically correct treatment of myths' can be expected to vanish in a puff of smoke. This is not least because behind all studies, articles, and books are interests, investments, institutions, types of desire and indeed types of authority, that are deep rooted. There are many examples of spurious histories and invented authenticities that could be discussed. But, I want to begin with reference to one of the most stark cases: a martial art structured by an antagonism between, on the one hand, an overwhelmingly fabricated or invented 'ancient' history, and, on the other hand, a growing body of academic studies that reveal its actual history to be little more than 60 years. This is the case of the Korean martial art and national sport, taekwondo. As with so many martial arts, the history of taekwondo is presented as ancient, indigenous, ethnic, autochthonous, and independent. But increasingly, historians of the art show that taekwondo cannot be said to have existed before the end of the Second World War. Indeed, it was elaborated primarily according to a nationalist and anti-Japanese post-war agenda. Ironically, however, taekwondo was constructed from ingredients found almost exclusively in the Japanese art of Shotokan karate. ${ }^{5}$ Nonetheless, taekwondo's status as an ideological part of Korea's de-Japanification is well documented. So are its founders' efforts to invent a history for it. Their project included, first, trying to persuade martial arts teachers in Korea to use their new name, 'taekwondo'; second, coming up with a persuasive (albeit spurious) etymology for the made-up characters of the new name; and, third, claiming that this modern practice had an unbroken connection with the martial arts of ancient legendary warrior kingdoms, folk traditions, indigenous sports, and heroic battles against invaders. ${ }^{6}$ In this narrative, the Japanese ingredients of taekwondo are erased, and Japan only features as the stooge within preposterous scenarios - such as the one in which taekwondo is said to have developed its high jumping kicks in order to kick samurais from their horses. As one martial arts writer puts it, you only have to have seen a horse, never mind someone sitting on it, never mind a warrior on a war-horse, to realize that this idea is ridiculous. ${ }^{7}$

Indeed, it is rather telling that it was only from the 1950s and 1960s that taekwondo began to spread around the world (Surely an older martial art would have been likely to have spread earlier). However, it soon becomes one of the most popular martial arts and martial sports internationally. One taekwondo institution (the World Taekwondo Federation [WTF], based in South Korea) became an Olympic sport. Another institution (the International Taekwondo Federation [ITF], based in North Korea) perhaps unsurprisingly chose to present itself instead as a lethal, pure, authentic killing art. In both incarnations, however, taekwondo has historical and nationalistic myth stitched through all of its elements. Its patterns (or kata) are named after and are given interpretations that relate to the ancient 
kingdoms that preceded the establishment of Korea, and students the world over must learn these names and related interpretations to pass their gradings. The inventors of modern taekwondo are presented as merely the modern links in a very old lineage, one that comes down to us unbroken through the ages. ${ }^{8}$ Given that all of this is in the syllabus, it is hardly surprising that practitioners of taekwondo believe all sorts of grand things about its history. But in this regard, of course, taekwondo is far from unique. Practitioners of all 'traditional' martial arts, from wherever, ${ }^{9}$ tend to believe in equivalent versions of magnificent histories. ${ }^{10}$

In this context, it seems pertinent to ask: what about scholars, academics, historians? What do they believe, write, and record? Unsurprisingly, in much scholarship on Asian martial arts, the matter of history remains freighted and weighted down by the same popular myths; so much so that even much that passes for scholarship seems to refuse to face up to the evidence that suggests that, quite frequently, martial arts that present themselves as ancient are hardly even old. ${ }^{11}$ So many massive social mutations occurred through the nineteenth and twentieth centuries that most 'traditional' martial arts effectively have at best little more than a century of continuous history to them, rather than the vast eons of allochronic time that so many seem to want them to have spanned. ${ }^{12}$

I emphasize the word 'want', here. This is because wanting appears to be a key issue to consider when approaching questions of martial arts history and culture. For instance, it seems that the perpetuation of fantasy histories and the fetishistic fabrication of lineages in 'traditional' martial arts evidently have everything to do with wanting. Practitioners want taiji to be ancient. Many want there to have been a Southern Shaolin Temple which was burned down, scattering the few surviving kung fu monks to the different corners of China. ${ }^{13}$ We want Okinawan farmers to have fought samurai with rice flails. We want Yim Wing Chun to have been a real proto-feminist warrior. ${ }^{14}$ We want the skill that wielded the weapon that killed Magellan to remain alive today. ${ }^{15}$ And we want ancient warrior armies to have flown at each other through the air, kicking each other off horses with flying sidekicks and jumping spinning back kicks. The interesting question, on which much academic work remains to be done, is why we want this, and why so much scholarship participates in perpetuating so many myths.

Obvious avenues of enquiry include the exploration of what Edward Said called orientalism, in both popular and scholarly discourses. ${ }^{16}$ And, against the hold of allochronic and orientalist desires, scholarship is increasingly waking up to orientalism and the inventedness of many traditions. But this is producing palpable disjunctions and antagonisms between emergent academic enquiries, much popular knowledge and certain older forms of scholarship. ${ }^{17}$

I have argued elsewhere that the emerging field of martial arts studies needs to adopt and develop disciplinary orientations that are different from and even sometimes in conflict with those of many 'traditional' academic disciplines, elsewhere. ${ }^{18}$ The reasons why become clear in this context, where we are faced with two different kinds of discourse, each claiming to be knowledge: ideological and mystical, on the one hand, versus verifiable and somewhat more prosaic, on the other. The importance of this reorientation relates to the significance of a fundamental - yet often overlooked - issue: namely, the question of what each of these kinds of knowledge does. My contention is that the orientation of martial arts studies should obviously not involve the perpetuation of trade in stereotypes, myths and ideologies, of course. But, equally, it should not just boil down to the making of better or more 'correct knowledge'. Rather, it should also involve what Stuart Hall called 'conjunctural analysis', 
which entails a thoroughgoing reflection on and study of the effects and the consequences of different kinds of knowledges as they intervene and circulate within different kinds of context in different kinds of way. ${ }^{19}$

There are clearly different kinds of context of and for historical knowledge. If we consider only taekwondo and Korea, we can see immediately why a post-Second World War Korea would want to distance itself from Japan, and why its military and other martial arts leaders might want to construct a new ancient history for themselves, free from Japan, and of course, implicitly, superior, or at least equal. ${ }^{20}$ We can also discern immediately why, still in the terms of nationalism and taekwondo, there were desires for the new invention to become a global sport. 'Taekwondo diplomacy' is surely no bad thing. At the same time, the emergence of the contrary desire, to remain free from the tarnish of 'sport' and to claim a purely martial character also makes sense, as emerged in North Korea. In both contexts, it makes obvious sense to go on to build museums, institutes, and exhibition centres, to 'educate' people about the art and its place within the culture; to commission research, to produce studies, and books, television programmes, documentaries, websites, and so on and so forth. It makes absolute sense for the new to become repackaged as the ancient, to represent the country, to capture hearts and minds, to become the heritage, with a centre, a Mecca for tourist-pilgrims, with ambassadors, embassies, annexes, and so on.

In such contexts, there is no guarantee that academic knowledge production can or will proceed independently or free from, say, state, governmental, political, economic or other kinds of coaxing and coercion - if indeed academia ever can. There are huge pressures and forces working on researchers in different places to conform to ideologies in all sorts of ways. For instance, in a study of taijiquan, Adam Frank points to the ways that Chinese academic studies of taiji, qigong, and qi in general overwhelmingly toe an ideological line in terms of the ways that these subjects are approached, which questions are brought to bear on them, and what conclusions are reached. ${ }^{21}$ This may seem dispiriting. For, what does it say about the purity and integrity of honest scholarship? ${ }^{22}$ Whatever our answers, we have to concede that there is big business, big PR, and myriad financial and ideological opportunities in nationalizing martial arts along self-orientalizing lines, as is clearly happening in such places as the PRC, Hong Kong, Japan, the Philippines, and both North and South Korea. ${ }^{23}$

\section{The Next Blow to Authentic, Traditional Martial Arts ...}

Having introduced these issues in a general way via this macro-focus on East Asia, it seems important to pose the question of whether and in what ways these issues, or versions of them, exist and operate at other levels and in other contexts. Consequently, in the remainder of this paper, I will consider one considerably less 'East Asian' case study, one that was played out over email and on an online social network, in the English language, between two authors, one Israeli, the other British, on the matter of two different English language books about martial arts. After exploring this case study, I will return to a reflection on the ramifications of the issues raised for our wider understandings of tradition, authenticity, history, and culture.

To begin, we might ask, what about other contexts - neither Asian nor national - where martial arts are not nationalist ideological interests? What is the situation between the two different orientations I have set out in other kinds of local, deracinated or transnational contexts? To broach this, I will bring this discussion as close to 'home' as I can. 
Early in 2015, I published a book (mentioned above), called Martial Arts Studies: Disrupting Disciplinary Boundaries. ${ }^{24}$ Almost as soon as the book was announced online, I was alerted by a friend that someone on Facebook was laying into me and my book. His settings were public, so anyone was able to see his post, and I was able to read it. The post was extremely thought-provoking, and I want to discuss it in this context. However, owing to its hostile tone, and the fact that posts on social media may be regarded as 'private' (certainly informal) even when settings are 'public', as well as for a number of other reasons, I felt reluctant to quote directly from the post. However, I have subsequently checked several times, and the post remains there. Most importantly, the settings are still 'public', and it is clear that the author uses his Facebook page to advertize and publicly promote his books, products, services and self, so I have decided to treat the post as a text that is in the public domain. Nonetheless (and despite a request from one of the peer reviewers of this paper), I have decided to leave the text anonymous, and not to give the author's name. This is because, as I hope will soon become apparent, my interest is less in who is saying what to whom about what, and more in why it is being said and what reflection on this example can teach us about competing discourses of power/knowledge - specifically authority - in the field of studies of martial arts. To be sure, I do not want to get into a public dispute. I do not feel aggrieved and have no score to settle. In actual fact I found the whole thing extremely stimulating. Consequently, for better or for worse, I quote the full post:

The next blow to authentic, traditional martial arts will not come from the pop-culture or the industry, but from pompous academics. Alongside many fine teachers who are pushing for real academic studies of the arts, there are now quite a few office nerds who have never punched a person in their lives, who wish to put martial arts under the microscope and examine them as if they were crystals in a tube. More and more do I see such people publishing 'scholarly articles', in which they talk about everything somehow related to the martial arts, besides all that matters. The martial arts are for these people simply obscure subjects of research, to which they can attach themselves to become 'academic experts' and write their Phd [sic] thesis.

One such person have [sic] just released a book called 'Martial Arts Studies: Disrupting Disciplinary Boundaries'. What the fuck does that have to do with martial arts? Look at the book's description:

The phrase 'martial arts studies' is increasingly circulating as a term to describe a new field of interest. But many academic fields including history, philosophy, anthropology, and area studies already engage with martial arts in their own particular way. Therefore, is there really such a thing as a unique field of martial arts studies?

Martial Arts Studies is the first book to engage directly with these questions. It assesses the multiplicity and heterogeneity of possible approaches to martial arts studies, exploring orientations and limitations of existing approaches. It makes a case for constructing the field of martial arts studies in terms of key coordinates from post-structuralism, cultural studies, media studies, and post-colonialism.

By using these anti-disciplinary approaches to disrupt the approaches of other disciplines, Martial Arts Studies proposes a field that both emerges out of and differs from its many disciplinary locations.

What the heck does this even mean? Who cares??

You know what that author wrote me when I offered he review my book, as he presents himself as a 'martial arts expert'? I will quote from his email. After he got a free copy, he wrote to me 
of the book: 'It's a bit outside of my areas, overall'. For me, that says everything of his level of 'expertise.'25

I leave the author of this public Facebook post from March 2015 anonymous for the reasons given in the paragraph preceding it.

Aside from everything else that is going on here, I want us to notice the bookishness of all of this. It is all about books. Yet, we tend to think that martial arts are about training bodies into weapons, how to use weapons, how to deal with weapons or withstand bodily weapons - 'body callousing', as it has been called. ${ }^{26}$ But what we see in this anecdote is not a bodily battle. It is, rather a battle over the book - ultimately, indeed, a dispute about authority, about kinds of authority. Each of us, my critic and myself, have a sense of what is a good book and what is a bad book, a right book and a wrong book. The problem is that, faced with each other's books, we do not agree on which is which.

As Jean-François Lyotard would once have said, there is a differend between us - a fundamental difference of opinion as to what is right and what is wrong; and moreover a difference that cannot really be settled without some damage being done to one or both of the parties. ${ }^{27}$ If we side with me, we damage him; if we side with him, we damage me. If we compromise in some kind of half-way settlement, we damage both of us. This is part of what Lyotard means by differend.

Noting this differend recasts my critic's opening salvo. It no longer looks so much like pure hyperbole. It now looks, surprisingly, like he may have a point. From his perspective: on the one hand, there are martial arts experts who are good teachers and good scholars. Because of this, they are authorized to write what will therefore be good books. On the other hand, there are office nerds with no martial arts mastery who are so ensnared in the academic machine that they can only write bad books. So this is the battle over the book: the determination of the proper book and the improper book. Behind the two books, two kinds of master: in the good corner, the true martial master with his true mastery; in the bad corner, the ignorant school master with his ignorant non-mastery - a non-mastery that abuses true master $y^{28}$ - and actually deals a blow to it. The inside of one realm is presented as the outside of the other: the inside of martial arts mastery is outside academic mastery; the inside of academic mastery is outside martial arts mastery. My critic's solution to the differend is the production of equal, symmetrical, simultaneous, and balanced mastery of both realms. So, as long as all writers have black belts with loads of dans on them, and at least one $\mathrm{PhD}$ each, then everything should be fine, right?

Unfortunately not. There are many writers of scholarly works on martial arts who (should they feel the need to do so) could claim both academic and martial arts expertise. (Fortunately, most understand that it is immodest to do so.) Unfortunately, these bordercrossing 'experts' all produce very different kinds of writing to each other. This is because, just as going to a particular martial arts class will draw you into a particular kind of behaviour (at least while you are there), so do different branches of academia. Hence, even experts in the same martial art, if they are working within different academic fields, will produce very different academic writing to each other, even if on ostensibly 'the same' subject. This is because different academic discourses each have their own distinct orientations, questions, concerns, methods, values, principles of verification and styles; and hence they each produce - or invent - their own specific 'disciplinary objects.' ${ }^{29}$ The kung fu of film studies is not the kung fu of historical studies which is not the kung fu of sports studies which is not the kung fu of philosophy or the kung fu of subcultural studies. This is why 
any and every piece of writing, when viewed from any other viewpoint, will always stand accused of - in my critic's words - 'talk[ing] about everything somehow related to the martial arts, besides all that matters'.

This is why, in my own book, I argued that the academic study of martial arts is always going to disappoint non-academic martial artist readers: academic writing about martial arts is never going to be simply about martial arts. It is always going to have to be also about something else - because academic writing can never simply be about one thing. ${ }^{30}$ The 'something else' that academic writing about martial arts could also (or ultimately) be about might include: identity, gender, ethnicity, class, nation, history, diaspora, globalization, media, technology, ideology, religion, philosophy, physiology, treatment of injury, rehabilitation, and so on and so forth, through many disciplines and the waxing or waning of many problematics structuring and restructuring each field. For, many - perhaps any - disciplines can accommodate studies of martial arts; but each will demand that the topic be formulated, explored, examined, and elaborated in terms of two crucial other things - first, one of that discipline's own preferred problematics, and, second, according to one of that discipline's approaches.

This is the source of the 'disconnectedness' of academic discourses, of course. But it is also the source of their connectivity, and of their capacities. On the one hand, academic studies of martial arts or anything else become disconnected from non-academic discourses when they vanish into their field's problematics. But, on the other hand, this supposed disconnect is precisely the source of their capacity to reconnect: the medical or mechanical study of the knee in taiji or taekwondo, or of blood pressure, or brain function, or the study of historical legislation around weapons, or political projects around street violence, and so on, might all come to have the capacity to intervene in 'the real world' precisely because of their principled drift or distance away from everyday discourses.

When it comes to my book, then, perhaps my critic has a point. Perhaps my kind of book is indeed part of striking a blow against all that he holds dear, up to and including his own claim to authority. Certainly, my kind of book takes aim at much of the baggage that goes along with certain 'traditional' ways of understanding tradition, authentic approaches to authenticity and authoritative understandings of authority; and the associated ways of 'preserving' these things, such as in certain kinds of 'traditional' or 'authentic' martial arts books. In the same way, methodologically rigorous studies of taekwondo and other martial arts could come to interrupt, disturb, and disrupt nationalistic discourses, if not at their points of production or popular reception, then at least in their academic moments and locations. ${ }^{31}$ For, if nothing else, such academic studies stand in stark contrast to both touristic-orientalist versions of martial arts histories and cultures, and the smooth deployment of such versions in ethnonationalist ideological fantasies, and the trade in emotive (and often emetic) evocations of 'history', 'tradition', and 'authenticity'. ${ }^{32}$

\section{History and Tradition in Theory and Practice}

The key point to be reiterated and developed is that despite their palpable and verifiable reality, neither history nor tradition are actually givens, simple referents or neutral entities. They are neither fixed nor permanent; they can be rewritten, revised, and transformed in any number of ways, just as they can be, and often are, used to manipulate and manage both people and practices. ${ }^{33}$ One or another version of this argument has been reiterated 
by historians, theorists, and philosophers so many times and in so many ways that all of these points could be said to constitute something of a commonplace in historical and cultural studies today. Traditions are invented, communities are imagined, culture can never be separated from management, and histories are rarely as long, pure, continuous or unbroken as many want them to be. Yet, as indicated earlier, some scholarship and a great deal of the discourse on traditional Asian martial arts often seems utterly resistant to many of the lessons of contemporary critical cultural theory and historiography. Traditional Asian martial arts are all too often believed to be ancient and exotic. But what happens when histories and other studies begin to challenge and dislodge these ideas, as when the results of such studies are disseminated via widely read para-academic sites, such as the popular blog Kung Fu Tea: Martial Arts History, Wing Chun and Chinese Martial Studies, ${ }^{34}$ for instance, or open-access academic journals, such as Martial Arts Studies? ${ }^{35}$ Another way to pose this question might be: what happens when everything you thought you knew about your martial art requires revision, or even complete rejection?

According to certain psychoanalytically-orientated cultural theorists, if too many of the certainties in our lives turn out to be false too quickly, this can have profound effects on our subjective stability and psychological well-being. ${ }^{36}$ So, what happens if the longterm practitioner of, say, taijiquan, learns that taiji is not actually ancient, unchanging and timeless, but rather more of a nineteenth-century ideological invention, and that the putatively ancient form they practice turns out to be no older than the 1980 s? ${ }^{37}$ Or what happens if a practitioner of Southern Shaolin learns that there was no Southern Shaolin Temple to be burned to the ground, and hence no few remaining monks to escape, and that all of the characters in the creation narratives and stories deriving from this are made up too? ${ }^{38}$ And what happens if the practitioner of Shotokan learns that Shotokan is really a twentieth century practice, ${ }^{39}$ or the practitioner of taekwondo learns that taekwondo was conceived, devised, and named in the 1950s and that it derives from no continuous indigenous tradition ${ }^{40}$

My questions may provoke some historians, and may cause many martial artists to stir. I may be greeted with incredulity, resistance, rejection. I may be disputed - and my claims met with counter-claims and assertions of different kinds of evidence. This is to be expected, indeed encouraged. But, at this level, the matter remains a fight between historians and ideologues, each disputing each other's evidence-claims, each denouncing the other as ideologue. Around these issues, it seems clear that there is currently a kind of war raging, between a belief in Asian martial arts as ancient, and a new wave of historians, who increasingly point out both the lack of evidence for claims of long continuous histories for many 'traditional' martial arts, and an abundance of evidence suggesting their rather recent invention. To state where I am in relation to this dispute, I will come clean and say that the romantic in me always wanted Asian martial arts to be really ancient, but the academic in me has to side with those who propose that history tends much more towards discontinuity and rupture than duration and continuity, ${ }^{41}$ that traditions are invented as ancient in the present, ${ }^{42}$ that lineages and heritages are established and instituted rather than inherited, ${ }^{43}$ and that communities are imagined, primarily so as to be more effectively managed. ${ }^{44}$

I cannot say that I was delighted when I first learned that the kung fu and taiji that I loved and practiced religiously in my thirties was not in fact aeons old, but effectively germinated and elaborated in the chaotic nineteenth century, and regularly reconstituted in the twentieth ${ }^{45}$; that the Shotokan karate I studied as a teenager was a twentieth-century 
formalization ${ }^{46}$; and that the taekwondo of my twenties is considerably younger than my own parents ${ }^{47}$ (By the time I met escrima in my forties, I had learned neither to ask nor to expect too much of history).

None of this made me happy. But it never stopped me training. Finding out that these histories were not chiefly matters of misty mountains, demigod warriors, and Taoist immortals caused definite pangs of disappointment. But I never stopped loving the skills I was learning. Yet part of me still wants my martial arts to be ancient. The question I want to explore at this juncture, then, is why. Why does the size of a history or length of a lineage matter so much, to so many people, in so many discourses about Asian martial arts? My aim at this point is not to dispute facts. It is rather to reflect on how and why, when and where, for whom and in what ways history matters. Do practitioners care about their martial art's history? Why should anyone care? Who is it who cares? What is it that such a care is a care of or a care for? In many cases, it does not actually seem to be a care for history at all: as my words have already suggested, what at least some people want, in wanting martial arts to date back millennia, does not seem to be history at all, but rather mythology. ${ }^{48}$ For, history is made of discontinuities, breaks, revisions, revolutions, reconstructions, reinstitutions, and reimaginings. Only in myth is there permanence and the feeling of temporal transcendence. This means that certain valuations of history are at root investments in myth.

Interestingly, in a preliminary discussion of the initial findings of an ethnographic study, Benjamin Judkins notes a distinct lack of interest in the history of kickboxing among the practitioners of at least one club in the US. Judkins himself is a long-time practitioner of wing chun kung fu, who researches and writes on the history of Southern Chinese martial arts, and is author of The Creation of Wing Chun: A Social History of the Southern Chinese Martial Arts ${ }^{49}$ In his initial discussion of kickboxers' relationship with their own practice's history, Judkins was evidently rather surprised to be greeted by the almost absolute lack of interest in kickboxing's history in his local club. If we were to generalize the implications of this, then we might be inclined to propose that traditional Asian martial artists either 'are' or 'come to be' (or perhaps 'learn to be') deeply invested in the sense of the history of their practice, while non-traditional martial artists seem to be rather less so, and seem rather more invested in alternative sets of concerns - such as efficiency for combat or competition, for instance. Of course, we may not be able to generalize from Judkins' anecdote. We may suspect that Judkins' reading involves a certain amount of projection, or 'confirmation bias', for instance, in which Judkins the-history-obsessed-scholar may be drastically inflating the value that he believes all or most practitioners of traditional Asian martial arts ascribe to their history. Or we may regard this case as too conspicuously isolated to have any generalizable value. But, as both I and others have argued elsewhere, there are a variety of kinds of evidence that might be called upon to support the idea of a kind of binary or antagonism between two different kinds of investment that structure martial arts discourses. This would be a binary or antagonism that can be formulated in terms of such couples as: history versus efficiency, or tradition versus innovation, and so on. ${ }^{50}$

One common way of organizing the binary involves spatializing, or imagining it in cultural or regional terms. Accordingly, 'the East' is said to 'value tradition' while 'the West' is said to 'value efficiency' and to happily deracinate, deconstruct, and reconstruct martial arts practices with a view to efficiency. ${ }^{51}$ But, of course, these binaries collapse as soon as one sees, on the one hand, the way traditions reconfigure and reconstitute themselves in the light of innovation, and, on the other hand, the way efficiency-focused institutions 
develop into traditions. So, the idea of 'tradition' that would see 'tradition' as somehow simply in opposition to 'change' is in itself perhaps a romanticization of 'tradition' - one that is perhaps in the sway of a kind of orientalist phantasy. But what is the phantasy? And whose is it? And why is it there?

\section{Self and Orient}

We have come to associate the notion of 'fantasies about Asian martial arts' with Western orientalism: the fetishistic obsession with the idea that Asian cultural practices are ancient and timeless. ${ }^{52}$ However, we have an obligation to look both ways, or at least to enquire further into the logics and engines driving so-called orientalism. ${ }^{53}$ So we must look not only at the orientalizing West but also at the often equally (self) orientalizing East ${ }^{54}$; and at other situations that complicate the western-orientalism paradigm. For instance, Adam Frank's study ${ }^{55}$ proposes that when Westerners (and I would add, Easterners too) practise Asian martial arts, part of their desire and part of the pleasure produced by practice relates to what he calls the sensuous feeling of and feeling for Chineseness (or, one might add, Japaneseness, or Koreanness, or even just generic Asianness). In other words, bound up in the desire to learn a traditional Asian martial art are Asiaphilic desires, orientalist fantasies, and allochronic imaginings of timeless embodied wisdom traditions. But, the point is: anyone can harbour these fantasies. So if we go down to our local dojo or dojang or kwoon, or join the taiji group in the park, part of what we are searching for is the feeling of what it is like to become a part of an ancient culture - to fantasize an involvement in that culture, in its ancientness - and to feel its embodied knowledge, techniques, movement systems, and 'wisdom', in our limbs, in our movements, and on our pulse.

Although this kind of structure of feeling seems more pertinent to martial arts like taiji than martial arts like taekwondo, nonetheless in all such cases a sense of 'history' is enormously important. ${ }^{56}$ Fantasies about 'history' are in a sense an integral part of the enjoyment. The longer the history, the better. This is because history functions within this orientation as a fetish category around, through and in terms of which practitioners fantasize. ${ }^{57}$ The age and origin of such arts become key coordinates in what Edward Said called an 'imagined geography. ${ }^{58}$

Note that 'history', here, is not an actually existing property of the world. It is an element of discourse. ${ }^{59}$ And notice also that, because 'the past is a foreign country', it can be 'orientalized', mythologized, idealized. This is why, in the countries of their origins, ideas of tradition in local martial arts can have ideologically powerful uses and abuses. Here, mytho-histories can easily feature as objects of regionalist or nationalist discourse. As Douglas Wile has argued convincingly, a large part of the intellectual, ideological, and philosophical elaboration of taijiquan in China during the nineteenth century can be understood as a symptomatic response to the perceived cultural threat that the west posed to China at that time. ${ }^{60}$ Similarly, Stephen Chan has argued that what he calls 'the Japanese cultural authorities' have long been more than happy to trade in orientalist myths in order to cash in on the assumption that all Japanese martial arts are ancient. And as more and more historians are showing, in the post-war (or post-wars) context(s) of both North and South Korea, the perceived need to both de-Japanify and to reconstruct a national culture was acute. It is in this context that the name 'taekwondo' was proposed, its obvious direct derivation from Shotokan disavowed, and extravagant claims made about its ancient and indigenous character. 
From this position, the supposed enigma or mystery of what has been called 'selforientalization' evaporates. Inventing 'ancient' traditions in the present actually makes perfect sense. As Rey Chow has argued, a fascination with the ancient, the pre-modern, and the primitive can often be read as a symptom of cultural crisis. ${ }^{61}$ Chow argues that 'primitive passions' are symptomatic of the chaotic or traumatic conditions of industrial modernity and postmodernity. In other words, passionate investment in ideas about ancient natives and their practices can be read as symptoms of anxieties about roots and identity in the present. ${ }^{62}$ In this light, 'history matters', in this kind of way, in contexts of untethered identity and anxious nationalism. But this kind of history very often boils down to what I have already called myth and what Jean-François Lyotard called 'narrative knowledge. ${ }^{63}$

For Lyotard, 'narrative knowledge' (or cultural/lineage knowledge) is not simply a matter of knowledge. It is also a matter of power. For, Lyotard argues, knowledge legitimates - both itself and also the institutions, practices, and people that it supports. In this sense, knowledge is a part of culture, and by the same token a force of politics. This much has been known for quite some time: Lyotard was writing in the 1970s, after all. But the question is: what has this got to do with traditional Asian martial arts? My contention is that a very great number of practitioners of avowedly 'traditional' and 'Asian' martial arts, have a great deal invested in the ideas of tradition and of specific areas of Asia. ${ }^{64}$ Even without the formalization of mythology within their curriculum, students pick up bits and pieces of what Lyotard calls 'narrative knowledge' - stories about lineage, masters, legendary fights, legendary locations, the proven superiority of 'our' art, and so on. This is precisely narrative/cultural knowledge in Lyotard's sense: words and phrases within language games that legitimate activities, values, hierarchies, and practices. In such language games, anything that casts established knowledge into doubt can precipitate not merely existential crisis but also institutional and cultural crisis. How do we proceed if our history (and hence sense of identity) is no longer what we thought it was?

For the martial arts practitioner, tradition and history are certainly not everything. Indeed, such considerations are precisely supplements in the sense given to the term by Derrida: things from the outside that add to and add on but in a way complete and fill a lack. ${ }^{65}$ But, the inside of martial arts practice seems clearly to be identified with the practice itself - the physical practice - the training, the sparring - the embodiedness of the practice. ${ }^{66}$ In other words, martial arts and martial artists do not in and of themselves need history. Grand historical narratives are not necessary to the legitimation and legitimization of martial arts. Such narratives primarily legitimate and legitimize other things anyway: institutional hierarchies, ethnonationalist myths, nationalist structures of feeling, film fantasies, tourist industries, and so on. So, what does the martial artist actually 'need'?

\section{Performativity}

Lyotard proposes that the key alternative and major antagonist facing 'narrative knowledge' is what he calls 'scientific knowledge'. Scientific knowledge, for Lyotard, does not depend principally upon narratives, such as history or lineage, for its legitimation - although narrative cannot be removed entirely from it. Rather, scientific knowledge is legitimated through performativity - through the performative, regular, stable, and predictable demonstration of efficiency and effectiveness. And I think that this provides us with the 
clue necessary for establishing the source of alternative approaches to the legitimation of martial arts: their performative efficiency.

Most martial arts claim not just narrative (historical) legitimacy but also, at the same time, often primarily, legitimacy based on efficacy. ${ }^{67}$ All practices taught as martial arts make some claim to practical combative or self-defence utility. The emergence of mediatized competitions such as the Ultimate Fighting Championship (the UFC) and other limitedrules full-contact martial arts competitions in the 1990s arguably pushed the matter of the public verification or verifiability of martial arts efficacy fully into martial arts discourse. ${ }^{68}$ Along with this, a range of online videos have depicted the disastrous outcomes for certain representatives of traditional or mystical martial arts - such as those of ' $q i$ masters' being battered by full-contact fighters, for instance. ${ }^{69}$ In other words, the full-contact arena has gained the status of Lyotard's science lab; and the digital camera and Internet serve to disseminate the results of many experiments. ${ }^{70}$ As such, the mediatization of martial arts challenges the legitimacy claims of many traditional martial arts, often revealing martial styles or institutions to have based their legitimacy claims on tautological values that cannot be subject to any kind of verification other than those they choose for themselves.

Ultimately, then, this is to point out two key things. First, that diligent historiography is revealing many martial lineages to be less than linear, many histories to be primarily stories, and many traditions to be at best disjointed and more commonly invented. ${ }^{71}$ Second, that the media saturation of daily life has thrust into the spotlight the question of the verification of the efficacy of martial arts. Both of these factors have transformed the discursive context, and hence induced a transformation at the 'genetic' level of martial arts. To clarify what this means, it may help to indulge in some crude periodizing for a moment. So, it might be proposed that the twentieth century saw certain 'traditional Asian martial arts' move first into fields of formalization: on the one hand, universities, schools, the police, the military, etc., and on the other hand, sport. From there they moved into film, and hence deeper into mythology. They also moved into discourses of lifestyles, belief-systems, self-improvement and, of course, self-defence. Now, however, the twenty-first century is seeing, on the one hand, the mytho-histories that were invented during these periods come under academic scrutiny, and on the other hand, the question of their performativity and efficacy coming under media and cultural scrutiny.

There are many other things going on at the same time, of course. I am not making totalizing claims. Discourses are contingent constellations of mobile and moving positions and possibilities, rather than linear narratives. And discursive constellations are always subject to internal and external pressures and forces, which hegemonize and orientate them - not unlike the ways that magnets can organize iron filings into constellations, shapes, and directions. In this sense, the hegemonic forces acting on and 'directing' martial arts discourses now include not only sportization, militarization, and senses of communing with the ancients, but also more intensive scholarly interrogation and more intensive mediatized interrogation. This means that the status of 'history' has been changed.

Of course, history always matters. We should always historicize. But this also means questioning the discursive status of history itself. And just as historical ignorance is deeply problematic, so too is ignoring a dearth of history, insisting on its presence, inventing it. Claiming an unbroken connection between something like modern taekwondo and pretwentieth century Korean kicking games, ${ }^{72}$ without facing up to the central presence of Shotokan via the Japanese military, is a bit like claiming an unbroken connection between 
people tapping their fingers on table tops throughout the ages and the invention of contemporary computer keyboards. Yet neither Microsoft nor Apple nor IBM nor Samsung nor anyone else needs to make this kind of narrative or lineage claim. History does not matter much in people's thinking about computer keyboards. This is because computer keyboards are legitimated principally by performativity - by efficiency and enjoyment ${ }^{73}-$ not by narrative.

Of course, neither performativity nor efficacy need boil down to cold, heartless, ruthless efficiency. When I take my youngest daughter down to the local karate club, where they teach a mixture of karate, taekwondo, and kickboxing, I know that what she is doing has about as much connection with Japan or Korea or indeed combat as when I take my other daughter to ballet. But this connection is not the point. The point is the pleasure. The pleasure is part of the efficacy. And this is important because the history of traditional Asian martial arts in the present only has a future by way of this pleasure.

In conclusion, what this paper has tried to emphasize is not only the problems and pitfalls of certain approaches to martial arts history, but also their connections with matters and mechanisms of power, authority, legitimation and other aspects of what may be called cultural politics. The contention is that the kind of approach advocated here - encompassing not only discernment and attention to fact and fiction but also the awareness of questions of power and pleasure in different kinds of context and conjuncture - can show how martial arts history matters in more ways and contexts than those of martial arts alone.

\section{Notes}

1. Most relevant to this paper, see, for example: Douglas Wile, Lost T'ai Chi Classics of the Late Ch'ing Dynasty (New York: SUNY Press, 1996); Benjamin N. Judkins and Jon Nielson, The Creation of Wing Chun: A Social History of the Southern Chinese Martial Arts (New York: SUNY Press, 2015); Udo Moenig, Taekwondo: From a Martial Art to a Martial Sport (London: Routledge, 2015).

2. The scholar who has perhaps done most to identify, discuss, and debunk many of the most tenacious myths and legends of Chinese martial arts is Stanley Henning. (See, for instance, Stanley Henning, 'Ignorance, Legend and Taijiquan', Journal of the Chen Style Taijiquan Research Association of Hawaii 2, no. 3 (1994), 1-7; Stanley Henning, 'On Politically Correct Treatment of Myths in the Chinese Martial Arts', Journal of the Chen Style Taijiquan 3, no. 2 (1995), 1-2; Stanley Henning, 'Academia Encounters the Chinese Martial Arts', China Review International 6, no. 2 (1999), 319-32; Stanley Henning, 'Martial Arts Myths of Shaolin Monastery, Part I: The Giant with the Flaming Staff', Journal of the Chen Style Taijiquan Research Association of Hawaii 5, no. 1 (1999), 1-4. Despite such efforts, however, countless books and all kinds of articles that present themselves as based on research continue to appear. As Henning's studies of even such an important scholar of Chinese history and culture as Joseph Needham indicate, many myths and legends that circulate in cultural discourses can easily seep into and skew even the most scholarly of works. For a discussion of the wider issues and theoretical significance of Henning's important study of Needham, see Paul Bowman, Martial Arts Studies: Disrupting Disciplinary Boundaries (London: Rowman and Littlefield International, 2015).

3. See, for instance, Cardiff University Press's open-access journal, Martial Arts Studies, which is at the forefront of this movement, http://martialartsstudies.org/, doi:10.18573/ISSN 20575696.

4. Henning, 'On Politically Correct Treatment of Myths in the Chinese Martial Arts', 1. It is important to note that in making this argument, Henning is not taking an isolated stand. In reflecting on the field of postcolonial studies, for instance, Rey Chow has frequently 
commented on the problem that arises when 'first world' academics feel obliged to maintain 'political correctness' by not challenging even the most problematic ethnonationalist and/ or racist positions voiced by certain ethnic subjects. See, for instance, Chow's discussions of political correctness on contemporary postcolonialist- and poststructuralist-informed academia, in Rey Chow, Ethics After Idealism: Theory, Culture, Ethnicity, Reading. Theories of Contemporary Culture (Bloomington, IL: Indiana University Press, 1998).

5. Of course, the nationalists who devised taekwondo through the 1950s did not merely rename Japanese moves and techniques. Rather, they preferred to modify and manipulate the techniques they all already knew from the Japanese styles, and claim that these forms were actually distinctly Korean. Hence, on the one hand, taekwondo blocks and strikes look remarkably like those of Shotokan, but they are just that bit different (and the differences are insisted upon). On the other hand, because Japanese kicks were low and conservative, a whole new repertoire of kicking techniques was invented. Indeed, one of taekwondo founder Choi Hong Hi's key criteria for allowing a kick into his syllabus was that it should not look like any of the kicks used in Japanese styles. See Alex Gillis, A Killing Art: The Untold History of Tae Kwon Do (Ontario: ECW Press, 2008); Moenig, Taekwondo.

6. Gillis, A Killing Art; Moenig, Taekwondo.

7. Raymond Rand, T'ai Chi Ch'üan: A Comprehensive Training Manual (Marlborough: The Crowood Press, 2004).

8. Moreover, its official history is highly selective: on a research trip in November 2015 to the taekwondo museum in the Taekwondowon in Muju, South Korea, I noted that one of the most instrumental and controversial players in the invention and dissemination of taekwondo, Choi Hong $\mathrm{Hi}$, was entirely absent from the museum. Given that some histories of taekwondo place Choi at the forefront of its development, his exclusion from the official national museum is telling. For what his absence from the official museum indicates is that Choi has been written out of the official historical narrative.

9. In the west, when we say 'traditional' martial arts, we normally seem to be evoking arts from China, Japan, Thailand, Korea, Indonesia, and the Philippines. This is because 'traditional martial arts' seems to be interchangeable with 'Asian martial art', and by 'Asian martial art' we seem to refer primarily to the styles that 'made it here', i.e. to the West. The list of such styles is short and selective.

10. For an interesting recent discussion of the role that Hollywood films play in the perpetuation of such beliefs, see Mie Hiramoto, 'Wax On, Wax Off: Commodification of Asian Masculinity in a Global Market Through Hollywood Films', Text \& Talk 35, no. 1 (2015), 1-23.

11. Stephen Chan, 'The Construction and Export of Culture as Artefact: The Case of Japanese Martial Arts', Body \& Society 6, no. 1 (2000), 69-74.

12. See also: Wile, Lost T'ai Chi Classics of the Late Ch'ing Dynasty; Douglas Wile, T'ai Chi's Ancestors: The Making of an Internal Martial Art (New York: Sweet Chi Press, 1999); Brian Kennedy and Elizabeth Guo, Jingwu: The School That Transformed Kung Fu (Berkeley, CA: Blue Snake Books, 2010).

13. The Southern Shaolin Temple is a staple myth in stories of the origins of Southern Chinese martial arts. It seems unlikely to have existed, but the lack of evidence does not deter the endless recycling of myths about it. See Meir Shahar, The Shaolin Monastery: History, Religion and the Chinese Martial Arts (Hawai'i: University of Hawai'i Press, 2008); Judkins and Jon Nielson, The Creation of Wing Chun.

14. Yim Wing Chun is the first practitioner of the new fighting style in the origin story of Wing Chun Kung Fu. See Judkins and Nielson, The Creation of Wing Chun.

15. The Portuguese explorer, Ferdinand Magellan (1480-1521), was killed during the Battle of Mactan in the Philippines in 1521. The fact that Filipino warriors (and 'hence' Filipino martial arts) were responsible for the demise of this important historical figure is often used to 'sell' the idea of the age and excellence of contemporary Filipino martial arts. On the history of Filipino martial arts, see Mark V. Wiley, Filipino Martial Culture (Clarendon, VT: Tuttle, 1996); Mark V. Wiley, Filipino Martial Arts: The Secrets of Cabales Serrada Escrima, rev. and expanded ed. (Boston, MA: Tuttle Pub, 2001). 
16. See E.W. Said, Orientalism: Western Conceptions of the Orient (London: Penguin, 1995 [1978]).

17. In this paper, we are dealing with history versus myth in martial arts history, but other (in) famous examples are the cases of qi or dim mak, for instance. See David A. Palmer, Qigong Fever: Body, Science and Utopia in China ([Kindle Edition] London: Hurst \& Co. in association with the Centre d'Etudes et de Recherches Internationales, Paris, 2007); Gary J. Krug, 'At the Feet of the Master: Three Stages in the Appropriation of Okinawan Karate into AngloAmerican Culture', Cultural Studies: Critical Methodologies 1, no. 4 (2001), 395-410; Adam Frank, Taijiquan and the Search for the Little Old Chinese Man: Understanding Identity through Martial Arts (New York: Palgrave Macmillan, 2006).

18. Bowman, Martial Arts Studies.

19. See, for instance, Stuart Hall, David Morley and Kuan-Hsing Chen, Stuart Hall: Critical Dialogues in Cultural Studies (London: Routledge, 1996).

20. As Benedict Anderson argues in Imagined Communities, in the modern world, nationalism really became the only game in town. 'Nations' had to play it for themselves, and for keeps, or someone else would play it for them, for keeps. And the invention of tradition and the imagining of community and continuity essentially involve what Derrida calls 'teleiopoeisis' and Said calls 'imagined geographies' - imagining and making grand claims about the past to glorify and justify the present. See Benedict Anderson, Imagined Communities: Reflections on the Origin and Spread of Nationalism, rev. ed. (London: Verso, 1991); E.J. Hobsbawm and T.O. Ranger (eds), The Invention of Tradition (Cambridge: Cambridge University Press, 1992, [1983]); Jacques Derrida, Politics of Friendship (London: Verso, 1997); E.W. Said, 'Invention, Memory, and Place', in Pepi Leistyna (ed.), Cultural Studies: From Theory to Action (Oxford: Blackwell, 2005), 256-69.

21. Frank, Taijiquan and the Search for the Little Old Chinese Man.

22. However, rather than reaching the dispiriting conclusion that academics working in intensely nationalistic contexts will produce implicitly or explicitly nationalist 'knowledge', I would prefer to think that Adam Frank's pioneering study of taijiquan will itself be read in China now, among the highly globally aware and English-language reading Chinese academics and students, and that as such his book constitutes a crucial and active contribution to the development of discourses about taijiquan, even in China.

23. As indicated earlier, 'self-orientalization' in Japan is discussed in Stephen Chan, 'The Construction and Export of Culture as Artefact: The Case of Japanese Martial Arts', Body \& Society 6, no. 1 (2000), 69-74, and in China in Frank, Taijiquan and the Search for the Little Old Chinese Man. There is ongoing research into these contexts. Similarly, ongoing research is being carried out on the self-orientalizing effects of UNESCO's 'intangible cultural heritage' on the discourse of martial arts such as wing chun in Hong Kong and Southern China. Similarly, the 2012 documentary The Bladed Hand, directed by Jay Ignacio, indicates the effects of both neglecting and 'nationalizing' martial arts in the Philippines.

24. Bowman, Martial Arts Studies.

26. Dale Spencer, Ultimate Fighting and Embodiment: Violence, Gender and Mixed Martial Arts (London: Routledge, 2011).

27. Jean-François Lyotard, The Differend: Phrases in Dispute (Minneapolis: University of Minnesota Press, 1988).

28. Jacques Rancière, The Ignorant Schoolmaster: Five Lessons in Intellectual Emancipation (Stanford: Stanford University Press, 1991).

29. John Mowitt, Text: The Genealogy of an Antidisciplinary Object (Durham: Duke, 1992); Bowman, Martial Arts Studies.

30. I hasten to add: the same goes for non-academic writing about them too - but a discussion about this now would take us too far afield. However, for a discussion of what I mean by this, see Alexander Hay, 'The Art and Politics of Fence: Subtexts and Ideologies of Late 16th Century Fencing Manuals', Martial Arts Studies, no. 1 (2015), 60-71.

31. Paul Bowman, 'Alterdisciplinarity', Culture, Theory and Critique 49, no. 1 (2008), 93-110.

32. It is in this way that I would most hope that the work of both me and my office nerd colleagues could indeed deliver the next big 'blow to authentic, traditional martial arts'. For, the authentic 
and traditional in this formulation seem to be valuable only to the extent that they remain mystified and occulted, and controlled by 'masters' with 'secret' and 'ultimate' and 'enigmatic' mysterious 'knowledge. This kind of knowledge is snake oil and shark fin, or rhino horn and tiger penis. All such things are precious, of course - and precisely because they are precious, they should not be consumed (I invite any who disagree with me, to try to kick me from my horse!). This is unlikely to be a threat to their continued existence, of course - just as the existence of sliced bread is really not a threat to the existence of bread knives. But it is a threat to their status, to their cultural capital, or indeed their brand. Put bluntly, my kind of book and his kind of book cannot coexist easily side by side. This is because, to borrow a phrase used by Stephen Chan in his keynote address at the martial arts studies conference at Cardiff University in June 2015, the academic study of martial arts (martial arts studies) is disciplinary rather than religious. (The video of Professor Chan's talk is available at: https:// goo.gl/R9HNAJ) This is a provocative binary, with a great deal condensed into it. 'Religious' here means, at the very least, based on belief, based on faith. It may also mean following rituals that work (as both Pascal and Althusser saw it) to produce belief where before the ritual there was none (Louis Althusser, Lenin and Philosophy and Other Essays (London: New Left Books, 1977)). It may also evoke, following Marx and Engels, the idea of religion as ideology, the opium of the people (Karl Marx and Friedrich Engels, The Communist Manifesto. Pelican Book (Harmondsworth: Penguin, 1967)). And so on. 'Discipline', on the other hand, is working in Stephen Chan's binary as 'the good guy': the rigorous, analytical force, chasing out superstition without reason. So, discipline - meaning academic discipline - stands opposed to and vigilant in the face of religion or religiosity. When he used this binary, Professor Chan was looking directly at me and addressing me, because I had only just finished talking about 'discipline' as less of a hero, less of a 'good guy'. In my own use of the term, in my introduction to the conference and to Chan's keynote, 'discipline' had been evoked as a kind of stultifying, streamlining, conservative force, drawing people's approaches and questions into a kind of conformity. However, I was not at that moment contrasting disciplined academic inquiry with religious faith. Rather, I had been depicting disciplines as stabilized, convention-loving, regulated and regulating institutions, and contrasting them with the exciting possibilities of a relatively chaotic and undisciplined cross-, inter-, and even anti-disciplinary nexus. However, clearly, when push comes to shove, both Stephen Chan and myself are on the side of all things academic - invested equally in ideas like rigour and critical questioning, demands for clear processes of verification, and so on.

33. Anderson, Imagined Communities; Hobsbawm and Ranger, The Invention of Tradition.

34. This professional and popular yet academic blog can be found at http://chinesemartialstudies. $\mathrm{com} /$.

35. This Cardiff University Press publication can be found at http://martialartsstudies.org/.

36. Judith Butler, Ernesto Laclau and Slavoj Žižek (eds), Contingency, Hegemony, Universality: Contemporary Dialogues on the Left (London: Verso, 2000).

37. Wile, Lost T'ai Chi Classics of the Late Ch'ing Dynasty; Wile, T'ai Chi's Ancestors.

38. Judkins and Nielson, Wing Chun; Douglas Wile, 'Review of Benjamin N. Judkins and Jon Nielson, The Creation of Wing Chun: A Social History of the Southern Chinese Martial Arts', Martial Arts Studies no. 1 (2015), 83-5.

39. Krug, 'At the Feet of the Master'; Chan, 'The Construction and Export of Culture as Artefact', 69-74.

40. Gillis, A Killing Art; Moenig, Taekwondo.

41. Thomas Kuhn, The Structure of Scientific Revolutions (Chicago: University of Chicago Press, 1962); Michel Foucault, The Order of Things: An Archaeology of the Human Sciences (London: Tavistock Publications, 1970).

42. Johannes Fabian, Time and the Other: How Anthropology Makes Its Object (New York: Columbia University Press, 1983); Anderson, Imagined Communities.

43. Rey Chow, The Protestant Ethnic and the Spirit of Capitalism (New York: Columbia University Press, 2002).

44. Hobsbawm and Ranger, The Invention of Tradition; Said, 'Invention, Memory, and Place'. 
45. Frank, Taijiquan and the Search for the Little Old Chinese Man; Kennedy and Guo, Jingwu.

46. Gichin Funakoshi, Karate-Do: My Way of Life (Tokyo: Kodansha, 1975); Krug, 'At the Feet of the Master', 395-410.

47. Gillis, A Killing Art; Moenig, Taekwondo.

48. Roland Barthes, Mythologies (London: Vintage, 1993); Anderson, Imagined Communities.

49. Judkins and Nielson, Wing Chun.

50. Paul Bowman, Theorizing Bruce Lee: Film-Fantasy-Fighting-Philosophy (Amsterdam: Rodopi, 2010); Paul Bowman, Beyond Bruce Lee: Chasing the Dragon through Film, Philosophy and Popular Culture (London: Wallflower Press, 2013); Bowman, Martial Arts Studies.

51. Daniele Bolelli, On the Warrior's Path: Philosophy, Fighting, and Martial Arts Mythology (Berkeley, CA: Blue Snake Books, 2003); Bowman, Theorizing Bruce Lee.

52. Said, Orientalism.

53. Chow, Ethics After Idealism.

54. Chan, 'The Construction and Export of Culture as Artefact', 69-74; John R. Eperjesi, 'Crouching Tiger, Hidden Dragon: Kung Fu Diplomacy and the Dream of Cultural China, Asian Studies Review 28 (2004), 25-39; Wile, Lost T'ai Chi Classics of the Late Ch'ing Dynasty; Wile, T'ai Chi's Ancestors.

55. Frank, Taijiquan and the Search for the Little Old Chinese Man.

56. However, on my visit to the Taekwondowon in November 2015, I was struck by the extent to which taekwondo was positioned not only as 'fun for children' (by way of pictures of cutesy animals wearing taekwondo uniforms) and hyper-gymnastic and sporty (via countless video screens showing amazing feats of taekwondo athleticism on a loop), but also as mystical and meditative, in an entirely orientalist mode, by way of video screens showing sequences of older practitioners sitting in meditative poses by rivers and atop mountains. All of which indicates the extent to which the South Korean taekwondo institutions are attempting to capitalize on a very wide range of 'brand values' for taekwondo, including full-blown orientalism.

57. Ernesto Laclau, 'Identity and Hegemony: The Role of Universality in the Constitution of Political Logics', in Judith Butler, Ernesto Laclau and Slavoj Žižek (eds), Contingency, Hegemony, Universality: Contemporary Dialogues on the Left (London: Verso, 2000); Said, 'Invention, Memory, and Place', 256-69.

58. Said, 'Invention, Memory, and Place', 256-69. The third term that triangulates and completes the picture is one's own place in relation to this ancient alterity in the present; namely, the self. Which is one obvious way in which Asian martial arts become bound up in identity - as coordinates of a fantasy life that structures values and activities.

59. 'Personal' discourse, first (communing with ancient civilizations is a private fantasy), but one whose raw materials and their configuration have come from a somewhat more public context - such as the vast and deep reservoirs of allochronistic and orientalist renderings of cultural or historical otherness. Fabian, Time and the Other.

60. Indeed, in Adam Frank's analysis of its status in China to this very day, taiji remains what he calls the quintessential symbol of Chineseness. Frank, Taijiquan and the Search for the Little Old Chinese Man.

61. Rey Chow, Primitive Passions: Visuality, Sexuality, Ethnography, and Contemporary Chinese Cinema (New York: Columbia University Press, 1995).

62. Chow, Primitive Passions. See also Bowman, Martial Arts Studies.

63. Jean-François Lyotard, The Postmodern Condition: A Report on Knowledge (Minneapolis: University of Minnesota Press, 1984).

64. Even the least research-inclined Western student of the least preachy instructor will doubtless harbour a vague sense of the ancientness of the art they practice. This is not alleviated in any way by martial arts institutions that require students to regurgitate verbatim mythological accounts of their art's history, in order to pass their belt/gradings, as is the case with taekwondo.

65. Jacques Derrida, Margins of Philosophy (Brighton: Harvester, 1982); Jacques Derrida, Monolingualism of the Other, or, the Prosthesis of Origin (Stanford, CA: Stanford University Press, 1998). 
66. However, many theorists have proposed that the essence of even apparently totally embodied practices are not simply bodily. As Slavoj Žižek argues, what drives physical activities is fantasy in the minds of practitioners: in the case of sex, it is the fantasies of both partners that determines and drives both desire and physical sex. So we cannot discount the importance of the ways that cultural fantasies work within us and organize our desires and pleasures. However, unlike Žižek, I would not stop there. For, we have to remember that, even if a sense of culture or history permeates our relation to a practice, and even if the grand lineage narrative of our style seems important or precious to us, our joys, pleasures, frustrations, and desires within that practice relate to the successful execution of a perfect technique with a perfect result. There is no getting away from the fact that executing a perfect head kick, sweep, throw, lock, choke or punch produces delight. And in these moments, fantasies of history or lineage are not at all present. The joy to be had in a jumping spinning kick does not depend on historical narratives. True, the source of the satisfaction derived from the physical event is undoubtedly to be found elsewhere by any kind of analyst: why someone wants to kick and why they derive delight from it can doubtless be psychoanalyzed, and different kinds of claims can be made about the origin and nature of the pleasure - whether it is regarded as coming from an individual's personal psychological make-up or whether it is regarded as exemplifying wider cultural pathologies (whether of patriarchy or phallocentrism). But, whatever other conscious or unconscious areas such pleasures relate to, the fact remains that martial arts practices do not need mytho-history for their legitimation.

67. See also D.S. Farrer, 'Efficacy and Entertainment in Martial Arts Studies: Anthropological Perspectives', Martial Arts Studies no. 1 (2015), 46-59.

68. Greg Downey, “As Real as It Gets!”: Producing Hyperviolence in Mixed Martial Arts', JOMEC Journal no. 5 (2014), 1-28.

69. Perhaps the most famous example is that of a 'ki master' who reputedly offered $\$ 5000$ to anyone who could beat him. The unfortunate video of that beating still circulates online, and can be found at: https://goo.gl/Hfcn03.

70. Dale Spencer, 'From Many Masters to Many Students: Youtube, Brazilian Jiu Jitsu, and Communities of Practice', JOMEC Journal no. 5 (2014), 1-12.

71. Hobsbawm and Ranger, The Invention of Tradition.

72. The narrative of taekwondo's development in South Korea almost always makes reference to the older kicking-based practice known as taekkyeon. Both Gillis and Moenig dispute the causal connection between an older taekkyeon and a newer taekwondo; and Moenig even goes so far as to dispute the survival of a living tradition of taekkyeon into the twentieth century at all. However, my attention here is not on the question of the history of taekkyeon, or its use and abuse in the creation narrative of taekwondo (although I do believe it has been used and abused), but rather on the tendentious manipulation of history itself to produce certain kinds of deliberate visibilities and invisibilities.

73. The allusion here is to Farrer, 'Efficacy and Entertainment in Martial Arts Studies'; and through this allusion, readers of Farrer's text may be able to perceive the basis of my critique or deconstruction of his binary of 'efficacy versus enjoyment'.

\section{Acknowledgements}

I owe thanks to the Korean Association of Martial Arts and Professor Fan Hong for inviting me to give a keynote address at the conference 'Martial Arts and Traditional Sports in Asia: History, Politics and Culture', held in the Taekwondowon, Muju, South Korea, 21-22 November 2015. This invitation allowed me carry out further research into the official curation of the history of taekwondo and other martial arts in South Korea. I would also like to thank Professor Michael Molasky for inviting me to present to a Research Group Meeting at Waseda University, Tokyo, in March 2016, as 
part of the collaborative research project, 'East Asian Martial Arts as Global Culture: Transmission, Representation, and Transformation in Japan, the US, and the UK' (「グローバル文化としての 東アジア武術一日・米・英における伝授、表象、変容」). This invitation enabled me to carry out further research relevant to this paper.

\section{Disclosure statement}

No potential conflict of interest was reported by the author.

\section{Notes on contributor}

Paul Bowman is a professor of cultural studies at Cardiff University, UK. 